\title{
BMJ Open Proposal of quality indicators for cardiac rehabilitation after acute coronary syndrome in Japan: a modified Delphi method and practice test
}

\author{
Shosuke Ohtera, ${ }^{1}$ Natsuko Kanazawa, ${ }^{2}$ Neiko Ozasa, ${ }^{3}$ Kenji Ueshima, ${ }^{4}$ \\ Takeo Nakayama ${ }^{1}$
}

To cite: Ohtera S,

Kanazawa N, Ozasa N, et al. Proposal of quality indicators for cardiac rehabilitation after acute coronary syndrome in Japan: a modified Delphi method and practice test. BMJ Open 2017;7:e013036. doi:10.1136/bmjopen-2016013036

- Prepublication history for this paper is available online. To view these files please visit the journal online (http://dx.doi.org/10.1136/ bmjopen-2016-013036).

Received 14 June 2016 Revised 10 January 2017 Accepted 12 January 2017

CrossMark

For numbered affiliations see end of article.

Correspondence to Shosuke Ohtera; ohtera.shosuke. 2n@kyoto-u.ac.jp

\section{ABSTRACT}

Objectives: Cardiac rehabilitation is underused and its quality in practice is unclear. A quality indicator is a measurable element of clinical practice performance. This study aimed to propose a set of quality indicators for cardiac rehabilitation following an acute coronary event in the Japanese population and conduct a small-size practice test to confirm feasibility and applicability of the indicators in realworld clinical practice.

Design and setting: This study used a modified Delphi technique (the RAND/UCLA appropriateness method), a consensus method which involves an evidence review, a face-to-face multidisciplinary panel meeting and repeated anonymous rating. Evidence to be reviewed included clinical practice guidelines available in English or Japanese and existing quality indicators. Performance of each indicator was assessed retrospectively using medical records at a university hospital in Japan.

Participants: 10 professionals in cardiac rehabilitation for the consensus panel.

Results: In the literature review, 23 clinical practice guidelines and 16 existing indicators were identified to generate potential indicators. Through the consensus-building process, a total of 30 indicators were assessed and finally 13 indicators were accepted. The practice test $(n=39)$ revealed that $74 \%$ of patients underwent cardiac rehabilitation. Median performance of process measures was $93 \%$ (IQR 46$100 \%)$. 'Communication with the doctor who referred the patient to cardiac rehabilitation' and 'continuous participation in cardiac rehabilitation' had low performance (32\% and $38 \%$, respectively).

Conclusions: A modified Delphi technique identified a comprehensive set of quality indicators for cardiac rehabilitation. The single-site, small-size practice test confirmed that most of the proposed indicators were measurable in real-world clinical practice. However, some clinical processes which are not covered by national health insurance in Japan had low performance. Further studies will be needed to clarify and improve the quality of care in cardiac rehabilitation.

\section{Strengths and limitations of this study}

- This is the first study to assess the utility of a whole set of quality indicators for cardiac rehabilitation that were established with the RAND/UCLA appropriateness method.

- A guideline-based modified Delphi technique was used and medical records were reviewed as a practice test before implementing indicators in real-world clinical practice.

- The composition of our panel members may lead to a biased selection of indicators.

- The single-site, small-size practice test may limit to generalise the performance of indicators.

\section{INTRODUCTION}

Acute coronary syndrome is a leading cause of death and a major social burden in the world. ${ }^{1}$ Developments in coronary interventions, surgical procedures, pharmacological treatments and lifestyle modifications (eg, smoking cessation) have improved prognosis, prevented recurrence and reduced mortality in patients who experience acute coronary events. ${ }^{23}$ In urban and/or suburban areas of Japan, however, the incidence of myocardial infarction and sudden cardiac death among men has increased in the past few decades, although the trend in rural areas is unclear. ${ }^{4-6}$

Previous studies have demonstrated the effectiveness of comprehensive cardiac rehabilitation (CR) on the survival and quality of life of patients with coronary heart disease. ${ }^{7}$ Yet CR referral rates vary according to characteristics of patients, specialty units and hospitals. ${ }^{8-14}$ Moreover, little is known about the quality of programmes in realworld clinical settings.

Quality indicators are measurable elements of practice performance for which there is evidence or consensus. Process indicators, in 
particular, are used to express the proportion of patients who receive appropriate care. They can highlight and reveal quality issues, which in turn enable the formulation of solutions for improvement. ${ }^{15-17}$ The use of quality indicators has increased in Japan, particularly in cancer care settings. ${ }^{18}$

Quality indicators for cardiovascular disease prevention and CR have been developed in European countries, the USA and Canada, but not in Asia including Japan. ${ }^{19-23}$ Additionally, a practice test prior to real usage is needed when developing quality indicators. ${ }^{24} 25$ However, previous practice tests examined only a part of the indicator set in the CR field. ${ }^{26} 27$

This study aims to (1) propose quality indicators for CR following an acute coronary event (eg, acute myocardial infarction and unstable angina), as these diseases are the most common indications for CR, (2) conduct a smallsize, pilot practice test with the whole set of the proposed indicators to confirm the feasibility and applicability before using them in real-world clinical practice and (3) describe a detailed process of developing quality indicators for applicability to other clinical circumstances.

\section{METHODS}

\section{Indicator development}

\section{Overview of the development process}

This study was conducted by the task force on evidencebased healthcare and clinical practice guidelines under the Ministry of Health, Welfare and Labour in Japan. The aim was to propose the common method to develop quality indicators.

A modified Delphi technique (the RAND Corporation (RAND)/University of California, Los Angeles (UCLA) appropriateness method), which has been widely used to develop healthcare quality indicators, was used. ${ }^{28}$ The method integrates an evidence review, a face-to-face multidisciplinary panel meeting and repeated anonymous rating for consensus building.

\section{Systematic search of evidence}

Kötter $e t a l^{4}$ previously reported that methods for quality indicator development based on clinical guidelines are increasing and may help in the efficient gathering of evidence when considering indicators. On this basis, we searched existing clinical practice guidelines available in English or Japanese and quality indicators related to CR after an acute coronary event developed in countries other than Japan. Specifically, we searched electronic databases with the search terms 'cardiovascular disease', 'cardiovascular system', 'cardiology', 'cardiac', 'cardiovascular' and 'rehabilitation' in August 2011. The following databases were used: one quality indicator database (Agency for Healthcare Research and Quality (AHRQ) National Quality Measures Clearinghouse); nine guideline databases (AHRQ National Guideline Clearinghouse, National Institute for Health and Care Excellence (NICE) Find Guidance, National Health
Service (NHS) Evidence, Minds, PEDro, Guidelines International Network, Australian Government National Health Medical Research Council, Canadian Medical Association and British Intercollegiate Guidelines Network) and three medical literature databases (MEDLINE, CINAHL and ICHUSHI). The Japanese Association of Cardiac Rehabilitation website and the Japanese Circulation Society website were also reviewed for Japanese guidelines on CR. The search was limited to the English or Japanese language. In 2011, we searched literature published from April 2006 to March 2011, because clinical guidelines are generally outdated after 5 years. ${ }^{29}{ }^{30}$ Two appraisers (SO and NK) evaluated the quality of the selected guidelines with the AGREE II instrument, which is the established tool for this purpose. ${ }^{31}$ For each guideline, overall assessments using AGREE II by two appraisers were averaged.

In order to generate indicators to be evaluated in a subsequent consensus panel, clinical practices which were strongly recommended in the selected guidelines were extracted. They were merged with existing quality indicators and applied to a structured format of the modified American College of Cardiology (ACC)/ American Heart Association (AHA) methodology. ${ }^{32}$ One researcher $(\mathrm{SO})$ assembled the indicators and was supervised by two experts: TN, an epidemiologist experienced in the development of a variety of Japanese clinical practice guidelines and also the chair of the task force on evidence-based healthcare and clinical practice guidelines, and $\mathrm{KU}$, a cardiologist familiar with $\mathrm{CR}$ and evidence-based medicine.

\section{Multidisciplinary panel}

Panel members responsible for consensus development were selected from registered instructors of CR licensed by the Japanese Association of Cardiac Rehabilitation. Licensure status requires individuals to have practised CR for at least 1 year, submitted 10 case reports and passed an authorised examination. To assemble the multidisciplinary group, we attempted to select more than one person from each profession related to CR (cardiologists, nurses, physical therapists, clinical laboratory technicians, registered dietitians, health fitness programmers and clinical psychologists). The sampling strategy was non-random selection aiming to seek participants who would be informative, with recommendations by $\mathrm{KU}$ and approval by $\mathrm{SO}$ and $\mathrm{TN}$. KU was a member of the committee on Japanese guidelines for CR and appointed as president of the Japan Association of Cardiac Rehabilitation in 2014. Each panel member signed a consent form for the present study. The indicator development part of this study was approved by the Kyoto University Graduate School and Faculty of Medicine, Ethics Committee.

\section{Consensus building}

On the basis of the modified Delphi technique, panel members formed a consensus regarding indicators in 
three rounds. In round 1, members individually evaluated indicators using a nine-point scale postal questionnaire. In round 2, they reconvened for a 1-day face-to-face meeting to discuss, revise and individually evaluate potential indicators, and then suggest additional ones at a later meeting. In round 3, they discussed additional indicators by email instead of a face-to-face meeting and evaluated them with the same postal questionnaire as above.

\section{Round 1}

A set of documents that described the quality indicators was distributed to 10 panel members. Members were then given 2 weeks to individually rate each indicator with a nine-point scale questionnaire, adapted from the nine domains suggested by Spertus et al: ${ }^{32}$ evidencebased, interpretable, actionable, denominator, numerator, validity, reliability, feasibility and overall assessment. We planned more than one reminder with email or telephone for non-responders.

\section{Round 2}

A 1-day face-to-face panel meeting was held. Panel members anonymously shared their results from round 1 and discussed each indicator. When the panel members felt the necessity, they revised the elements of each potential indicator considering a member's suggestion. Any disagreements were resolved through discussion. Finally, the panel rated the revised indicators individually, using the same questionnaire from round 1. At the end of the meeting, we asked members to suggest additional indicators that might be important for measuring the quality of CR services in Japan that had not been examined by the panel prior to the meeting.

\section{Round 3}

Additional indicators were developed from suggestions during the panel meeting (round 2). A document describing the new indicators was sent to panel members electronically, asking for any modifications. The indicators were then revised according to the suggestions and sent to panel members by mail to rate using the same questionnaire from round 1.

\section{Selection criteria}

Quality indicators were adopted according to the following criteria: the median individual rating during round 2 or 3 was $>7$, and the number of panel members who gave a rating $<3$ was two or fewer.

\section{Pilot practice test for feasibility and adaptability Study patients}

Selected patients were those who (1) experienced an acute myocardial infarction or unstable angina and (2) were admitted to Kyoto University Hospital, which provides acute-to-recovery care in Japan, between 1 January 2013 and 30 June 2013. On the basis of the Ethical
Guidelines for Epidemiological Research established by the Ministry of Education, Culture, Sports, Science and Technology and Ministry of Health, Labour and Welfare in Japan, we prepared a protocol mentioning that the investigators disclose requisite information on the study and, consequently, the protocol for the practice test was approved by the university ethics committee.

\section{Data collection}

Data were collected from Kyoto University's electronic medical records in January 2014. Records regarding eating habits (QI-2), coronary risk factors (QI-3), psychological responses (QI-4), tobacco and alcohol (QI-5), exercise capacity (QI-6), definition of the programme end period (QI-8), and work and leisure (QI-10) were available in the implementation planning sheets for CR per national insurance regulations. Professionals assessed a suitable period with regard to QI-8 for every patient in view of their clinical situation and recorded it in the planning sheet as routine in the hospital. Records on education regarding the importance of adherence to prescription medication (QI-12) were available in pharmacist instruction reports, also per national insurance regulations. SO and NK assessed performance of the indicators based on each patient's records. Disagreements were resolved by discussion.

\section{Data analysis}

Patients with acute myocardial infarction and unstable angina were selected consecutively during the study period from Kyoto University Hospital via coronary catheterisation records for measurement with the indicators. Percentage scores were obtained for each indicator as follows: the number of times the indicator was met/the number of participants (excluding those with obvious reasons for not implementing the process as defined by the indicator $\times 100$. Medians of indicator scores were also computed as an overall quality score of the programme.

\section{Disclosure and update}

The adopted indicators were disclosed and externally reviewed at a symposium during the annual meeting of the Japanese Association of Cardiac Rehabilitation, of which KU was the president in July 2014. Considering suggestions from external experts, an indicator regarding referral to CR was updated in October 2015 based on an online panel discussion and the nine-point scale assessment.

\section{RESULTS}

\section{Quality indicators}

The literature review identified 38 quality indicators from the AHRQ National Quality Measures Clearinghouse, of which 16 were selected according to the criteria (figure 1). Searches of guideline databases and medical literature databases identified 894 articles 
Figure 1 Flow chart of the literature search. *Agency for Healthcare Research and Quality National Quality Measures Clearinghouse. †The Japanese Association of Cardiac Rehabilitation website and the Japanese Circulation Society website.

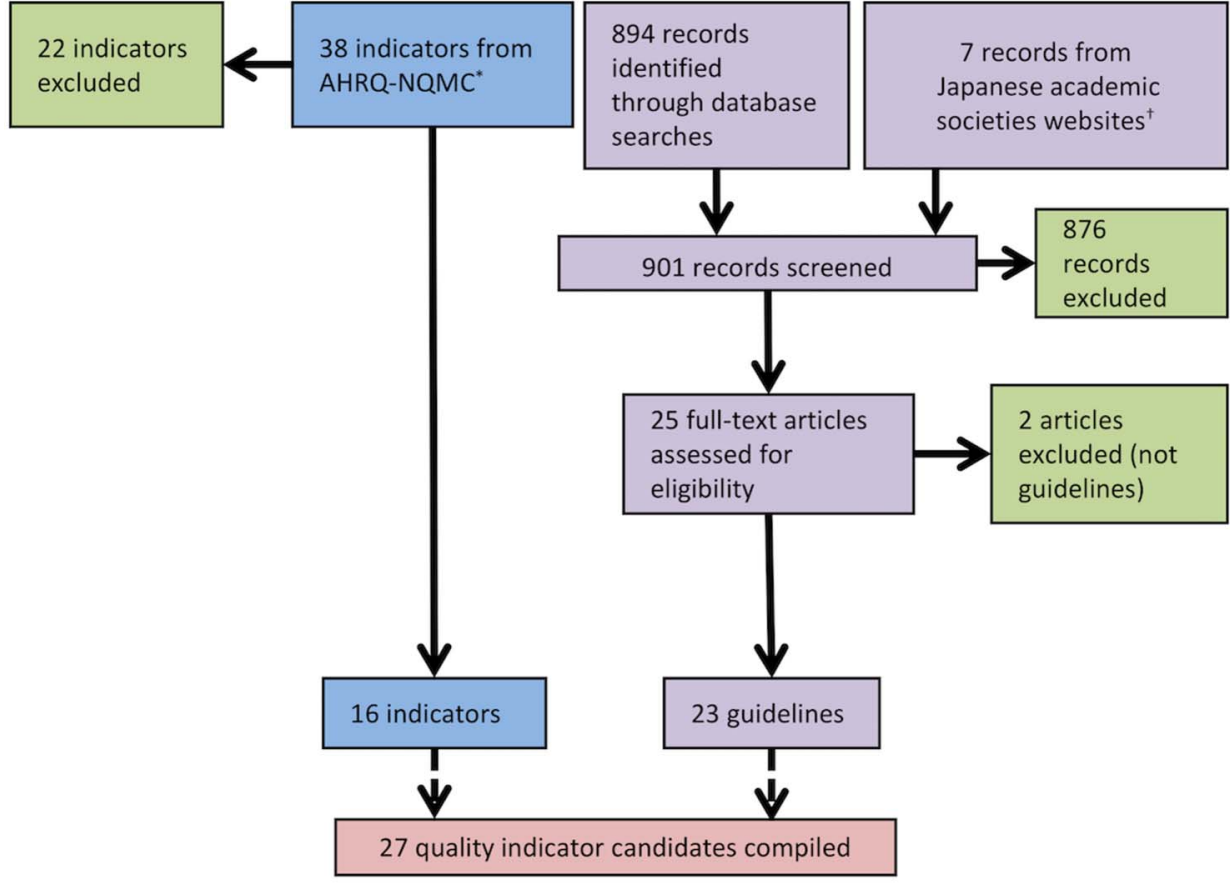

(103 from the AHRQ National Guideline Clearinghouse, 121 from NICE Find Guidance, 487 from NHS Evidence, 2 from Minds, 11 from PEDro, 25 from the Guidelines International Network, 6 from the Australian Government National Health Medical Research Council, 9 from the Canadian Medical Association, 22 from the British Intercollegiate Guidelines Network, 74 from MEDLINE, 24 from CINAHL and 10 from ICHUSHI). Seven additional guidelines were identified from the Japanese academic society websites. In total, 23 guidelines met our eligibility criteria. The average of overall quality scores based on AGREE II was 5.0 out of a possible 7 (minimum to maximum 3.5-6.0). A total of 27 potential indicators created from the aforementioned 16 existing indicators and 23 guidelines were included for panel assessment. ${ }^{33-55}$

Ten Japanese clinicians in CR were invited to the panel, including two cardiologists, two nurses, two physical therapists, one clinical laboratory technician, one registered dietitian, one health fitness programmer and one clinical psychologist (a member of the committee on Japanese guidelines for CR). Finally, all of them participated in the consensus development process.

The round 2 ratings accepted six indicators (figures 2 and 3). Although an indicator regarding referral to CR from outpatient settings had been discarded in this round, it was later accepted in the update period as a modified indicator (QI-1, table 1), the rating of which was a median of 8 , and minimum to maximum of 4-9 (figure 3).

The panel had a debate about the arrangement of indicators regarding coronary risk factors. The members understood the importance of assessment and education for each risk factor. However, at the same time, they concerned measurement burden in clinical practice due to

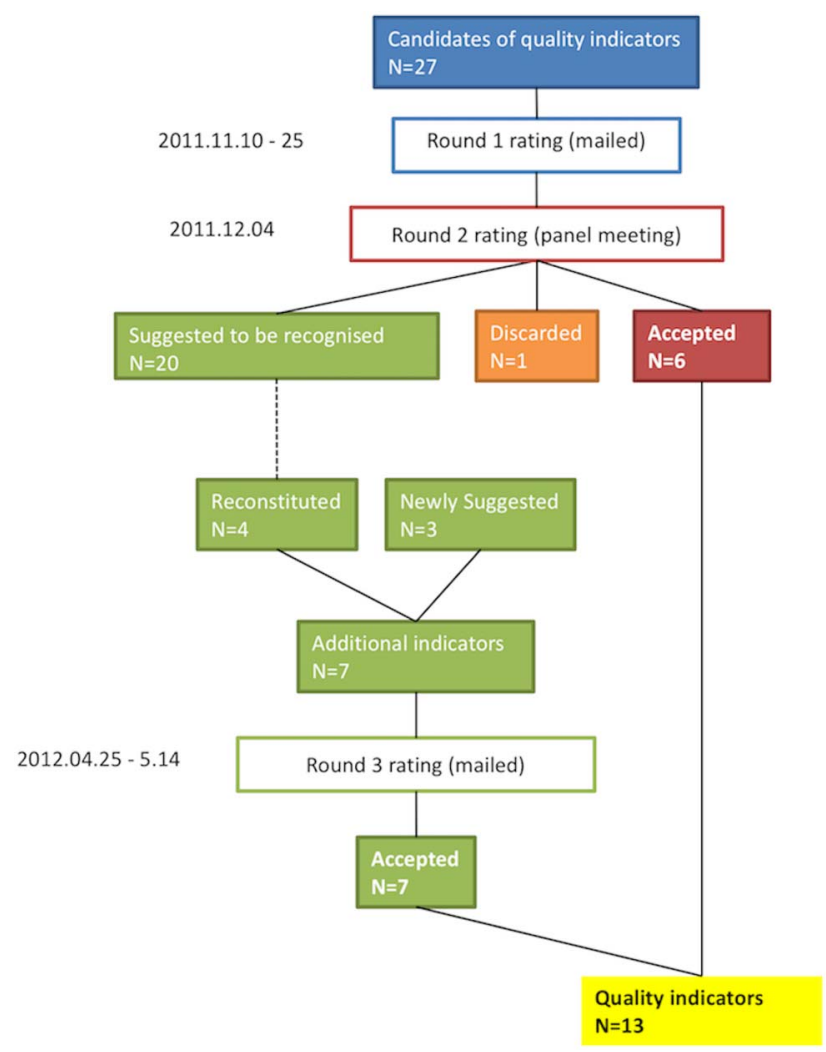

Figure 2 Flow chart of quality indicator selection.

a lot of indicators. They considered that practitioners, generally in Japan, assess coronary risk factors comprehensively and arrange education programmes for individual patients. Finally, the indicators were grouped as follows: (1) chronic disease as coronary risk factors and the preventive behaviour, (2) consumption of 
Figure 3 Rating distribution of candidate indicators. The $\mathrm{X}$-axis indicates individual indicator evaluation by the panel (1: disagree, 9: agree). The $\mathrm{Y}$-axis indicates the number of panel members who scored the indicator. ${ }^{*}$ This candidate indicator did not gain consensus and was discarded in round 2 . †This was an updated indicator that includes referral from outpatient settings as well as inpatient settings.
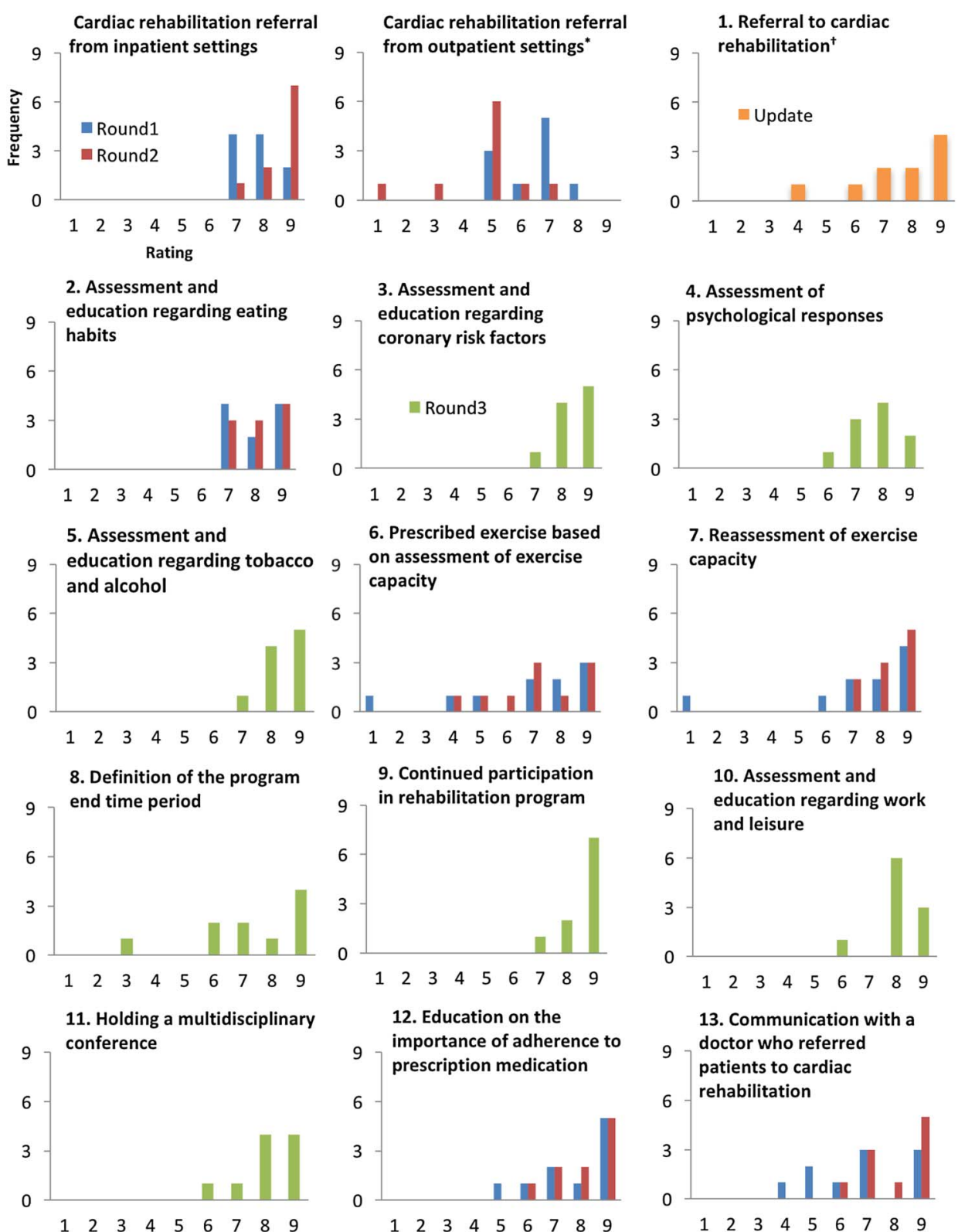

non-essential grocery items which increases coronary risk, such as tobacco and alcohol, and (3) psychological responses.

Of the 20 primary indicators, the panel reconstructed four indicators. The indicator 'assessment and education regarding coronary risk factors' was developed by combining the following 13 primary indicators: 'hypertension assessment', 'education for patients with hypertension', 'target blood pressure goal achievement', 'assessment and education regarding blood lipids', 'reassessment of blood lipids', 'assessment and education regarding physical activity habits', 'intervention for physical activity habits', 'reassessment of physical daily activity', 'assessment of body weight', 'intervention for body weight control', 'assessment of diabetes', 'intervention for diabetes', and 'target glycated haemoglobin goal achievement'. Some panel members noted that clinicians tend to deal with these issues together rather than separately. As such, they agreed that combining these indicators would make it easier to perform highquality measurements. The panel agreed that you judge to be met the criteria when there is a record regarding assessment and education on at least one of the coronary risk factor aforementioned or a record that a patient have none of the risks.

The two primary indicators, 'assessment of depression' and 'intervention for a patient suspected of having depression', gave rise to the indicator 'assessment of psychological responses'. Patients with coronary disease often have psychological issues such as depression, anxiety or insomnia. ${ }^{20} 56$ Furthermore, the panel was of the opinion that patients in Japan rarely receive appropriate assessments, aside from interventions they receive for CR.

The indicator 'assessment and education regarding tobacco and alcohol' was generated by combining the 
Table 1 Quality indicators and percentage scores for cardiac rehabilitation of inpatients with ischaemic heart disease

\begin{tabular}{|c|c|c|c|}
\hline Domains & Indicators & $\begin{array}{l}\text { Numerator/ } \\
\text { denominator }\end{array}$ & $\begin{array}{l}\text { Performance } \\
(\%)\end{array}$ \\
\hline \multirow{2}{*}{$\begin{array}{l}\text { Domain 1: referral to cardiac } \\
\text { rehabilitation }\end{array}$} & QI-1: referral to cardiac rehabilitation & $29 / 39$ & 74 \\
\hline & $\begin{array}{l}\text { QI-2: assessment and education regarding eating } \\
\text { habits }\end{array}$ & $29 / 29$ & 100 \\
\hline \multirow[t]{3}{*}{$\begin{array}{l}\text { Domain 2: modification of coronary risk } \\
\text { factors }\end{array}$} & $\begin{array}{l}\text { QI-3: assessment and education regarding } \\
\text { coronary risk factors }\end{array}$ & $29 / 29$ & 100 \\
\hline & QI-4: assessment of psychological responses & $28 / 29$ & 97 \\
\hline & $\begin{array}{l}\text { Q1-5: assessment and education regarding tobacco } \\
\text { and alcohol }\end{array}$ & $29 / 29$ & 100 \\
\hline \multirow[t]{2}{*}{ Domain 3: exercise therapy } & $\begin{array}{l}\text { QI-6: prescribed exercise based on assessment of } \\
\text { exercise capacity }\end{array}$ & $20 / 27$ & 74 \\
\hline & QI-7: reassessment of exercise capacity & $11 / 24$ & 46 \\
\hline \multirow{2}{*}{$\begin{array}{l}\text { Domain 4: completion of the cardiac } \\
\text { rehabilitation programme }\end{array}$} & QI-8: definition of the programme end period & $29 / 29$ & 100 \\
\hline & $\begin{array}{l}\text { QI-9: continued participation in the rehabilitation } \\
\text { programme }\end{array}$ & $8 / 21$ & 38 \\
\hline Domain 5: return to social activity & $\begin{array}{l}\text { QI-10: assessment and education regarding work } \\
\text { and leisure }\end{array}$ & $29 / 29$ & 100 \\
\hline $\begin{array}{l}\text { Domain 6: involvement of } \\
\text { multidisciplinary team }\end{array}$ & QI-11: holding a multidisciplinary conference & $14 / 29$ & 48 \\
\hline $\begin{array}{l}\text { Domain 7: management of prescription } \\
\text { medication }\end{array}$ & $\begin{array}{l}\text { QI-12: education on the importance of adherence } \\
\text { to prescription medication }\end{array}$ & $26 / 29$ & 90 \\
\hline $\begin{array}{l}\text { Domain 8: communication with other } \\
\text { healthcare providers }\end{array}$ & $\begin{array}{l}\text { QI-13: communication with a doctor who referred } \\
\text { the patient to cardiac rehabilitation }\end{array}$ & $8 / 25$ & 32 \\
\hline
\end{tabular}

following three primary indicators: 'assessment of tobacco use', 'support of smoking cessation' and 'education on alcohol'. The panel agreed that combining these items would improve measurement quality in clinical settings, as clinicians typically deal with these issues together. It also agreed that you judge to be met the criteria when there is a record regarding assessment of tobacco and alcohol use and education on them if it is necessary.

The primary indicator counselling to return to work was reworded as 'assessment and education regarding work and leisure'. The panel agreed that it was important for a patient requiring rehabilitation to enjoy leisure activities, in addition to returning to work.

In addition to the indicators discussed above, the panel suggested some indicators, including 'definition of programme end period' and 'continued participation in rehabilitation programme'. These indicators were generated after some panel members emphasised the importance of completing the CR programme. Given the multidisciplinary nature of the rehabilitation team, the generation of another indicator (holding a multidisciplinary conference) was suggested.

In the end, a total of 13 quality indicators were proposed. These indicators spanned the following domains: (1) referral to CR, (2) modification of coronary risk factors, (3) exercise prescription, (4) completion of the CR programme, (5) return to social activity, (6) involvement of a multidisciplinary team, (7) management of prescription medication and (8) communication with other healthcare providers (table 1 ).

\section{Performance in the pilot practice test}

Of the 39 assessed patients (22 with acute myocardial infarction and 17 with unstable angina), 29 (74\%) participated in a CR programme (QI-1, table 1). The median performance, based on QI-2 to QI-13, was 93\% (IQR 46-100). Indicators for which data are collected for national insurance claims (QI-2, 3, 4, 5, 6, 8, 10 and 12) showed high performance (median $100 \%$; minimum to maximum 74-100), whereas others, including QI-7, 9, 11 and 13, showed low performance (minimum to maximum, $32-48 \%$ ).

\section{DISCUSSION}

In this study, we proposed 13 quality indicators for assessing CR in patients who suffered from acute coronary syndrome in Japan. A widely used consensus approach, the modified Delphi method, with a Japanese multidisciplinary panel identified seven crucial domains for the quality measurement. On the basis of results of the single-site, small-size practice test, we found that most of the indicators proposed were measurable in real-world clinical practice and the performance for which data are collected for national insurance claims was high, whereas performance of indicators for which data are recorded voluntarily was low. 
The structure of our proposed indicators is consistent with those reported in previous studies. A few reports have been published that deal with quality measures for CR in North America. ACC/AHA/American Association of Cardiovascular and Pulmonary Rehabilitation (AACVPR) provided a performance measure set that has (1) referral to $\mathrm{CR}$ and (2) performance in the programme as major parts. $^{20} 21$ The Canadian Cardiovascular Society also originally developed quality indicators on CR, and then prioritised a list of five indicators, including (1) inpatients referred to CR; (2) wait times from referral to CR enrolment; (3) patient self-management education; (4) increase in exercise capacity and (5) emergency response strategy. ${ }^{22}{ }^{27}$ In this study, our set of indicators reflects the importance of referral to CR and a comprehensive programme. Therefore, we consider these to be essential elements of quality indicators for CR. Additionally, our study includes a measurement for the completion of CR, which is common with a measure set of the USA. It is because completion of the prescribed course of the programme is a key to promoting patients' lifelong behaviour change and physiological adaptations from regular exercise. ${ }^{20}$

During the process of developing quality indicators, pilot practice tests prior to implementation are important for determining which indicators become established components because they evaluate validity, reliability and feasibility. ${ }^{24}$ Some studies in other medical fields (eg, neck tumours, diabetes, pneumonia) have reported that, among accepted indicators in the development process, $\sim 10-30 \%$ were not measurable or inapplicable. ${ }^{5758}$ In the field of CR in the USA, Thomas et $a l^{26}$ revealed that reliability of the abstraction for the measure regarding referral was good to excellent. In addition, with respect to Canadian indicators, Grace et $a l^{27}$ assessed feasibility and concluded that the indicator assessment was acceptable for the CR programme. Unlike the previous studies, our practice test was smallsized but included all indicators proposed. Although the generalisability is limited, we found a possibility that some processes for which data were not recorded per healthcare insurance regulations have low performance. Therefore, the result suggests that incentives such as insurance coverage can improve performance in clinical practice and recording the process. Since Grace $e t a 2^{27}$ also reported that the information-tracking process was challenging when measuring quality, which may be a common issue in the field of CR across countries. Further studies will be needed to make quality measurements more appropriate and efficient.

Although panel nomination is one of the key elements of quality indicator development, many studies lack transparency in the process. ${ }^{24}$ To increase transparency, our study established the following explicit criteria: (1) the panel members must have an authorised licence from an academic society, (2) at least one member is selected from every relevant profession and (3) the panel involves some members who have experiences of CR guideline development. Finally, our panel included the people concerned with the committee on the clinical practice guidelines for CR jointly developed by the relevant academic societies in Japan (ie, Shunichi Ishihara and Shinji Sato who are respectively a member and collaborator of the committee).$^{59}$

In contrast to previous reports from the USA and Canada, our study did not directly stand on the initiative of any academic society. However, there were opportunities for authorised experts of CR to express his or her views into the present quality indicators.

The adaptability of each quality indicator must be reviewed before implementation because healthcare systems and social circumstances differ. This is a key element in evidence-based clinical decision-making. ${ }^{60} 61$ We consider, however, disclosing the explicit process of guideline-based quality indicator development, which is a time-efficient and resource-saving approach, ${ }^{24}$ will be helpful for people attempting to develop similar quality indicators in other regions or different social levels.

\section{CONCLUSION}

Using an explicit and integrated approach based on evidence and the consensus of a multidisciplinary panel, we proposed 13 specific indicators to measure the quality of CR for patients who experienced acute coronary events in Japan. The practice test was small-sized but helpful to confirm the measurability of all indicators proposed, and suggested that incentives such as insurance coverage can improve performance in clinical practice and recording the process. Further studies will be needed to clarify the reasons for this, as well as to improve the quality of care in CR.

\section{Author affiliations}

${ }^{1}$ Department of Health Informatics, Graduate School of Medicine/School of Public Health, Kyoto University, Kyoto, Japan

${ }^{2}$ Clinical Research Center, National Hospital Organization, Tokyo, Japan

${ }^{3}$ Department of Cardiovascular Medicine, Kyoto University Hospital, Kyoto, Japan

${ }^{4}$ Department of EBM Research, Institute for Advancement of Clinical and Translational Science, Kyoto University Hospital, Kyoto, Japan

Acknowledgements The authors thank the panel members for their contribution to the project: Hirokazu Shiraishi and Mai Munechika, University Hospital, Kyoto Prefectural School of Medicine; Harumi Konishi, National Cerebral and Cardiovascular Center; Chie Douke, Hayashi Heart Clinic; Yoshimi Matsuo, Mukogawa Women's University; Masaru Imai, Takeda Hospital Group; Shinji Sato, Osaka Sangyo University; Sawako Yoshiuchi, Kansai Medical University Hirakata Hospital; and Shunichi Ishihara, Bunkyo University. The authors also thank Takahiro Higashi, the National Cancer Center, for his advice on the manuscript, and Hiroshi Morishita, Morishita Heart Clinic, for his external review.

Contributors SO designed the study, collected and analysed the data, and drafted the manuscript. NK assisted the data collection and analysis, and the manuscript preparation. NO and KU contributed to the data collection and interpretation, and the manuscript preparation. TN supervised the study and gave the final approval of the manuscript.

Funding This work was supported by the Ministry of Health, Labour and Welfare Japan as follows: 'Research on roles and possibilities of clinical practice guidelines for dissemination of evidence-based medicine (H22-iryoushitei-042, 2010-2011)', 'Research on development of clinical practice 
guidelines based on systematic reviews and promotion of EBM in clinical practice (H24-iryou-shitei-051, 2012-2013)' and 'Research on the subjects of clinical practice guidelines to realise socially accountable healthcare (H26iryou-shitei-038, 2014-2015)'.

Competing interests None declared.

Ethics approval Kyoto University Graduate School and Faculty of Medicine, Ethics Committee.

Provenance and peer review Not commissioned; externally peer reviewed.

Data sharing statement No additional data are available.

Open Access This is an Open Access article distributed in accordance with the Creative Commons Attribution Non Commercial (CC BY-NC 4.0) license, which permits others to distribute, remix, adapt, build upon this work noncommercially, and license their derivative works on different terms, provided the original work is properly cited and the use is non-commercial. See: http:// creativecommons.org/licenses/by-nc/4.0/

\section{REFERENCES}

1. Turpie AG. Burden of disease: medical and economic impact of acute coronary syndromes. Am J Manag Care 2006;12(Suppl 16): S430-4.

2. Yeh RW, Sidney S, Chandra M, et al. Population trends in the incidence and outcomes of acute myocardial infarction. $N$ Engl J Med 2010;362:2155-65.

3. Kihara Y. After the triumph of cardiovascular medicine over acute myocardial infarction at the end of the 20th Century. Can we predict the onset of acute coronary syndrome? (Con). Circ J 2011;75:2019-26; discussion 18

4. Ohira T, Iso H. Cardiovascular disease epidemiology in Asia: an overview. Circ J 2013;77:1646-52.

5. Kojima S, Matsui K, Ogawa $\mathrm{H}$, et al. Temporal trends in hospitalization for acute myocardial infarction between 2004 and 2011 in Kumamoto, Japan. Circ J 2013;77:2841-3.

6. Wanezaki M, Watanabe T, Nishiyama S, et al. Trends in the incidences of acute myocardial infarction in coastal and inland areas in Japan: the Yamagata AMI Registry. J Cardiol 2016;68:117-24.

7. Heran BS, Chen JM, Ebrahim S, et al. Exercise-based cardiac rehabilitation for coronary heart disease. Cochrane Database Syst Rev 2011;(7):CD001800.

8. Bjarnason-Wehrens $B$, McGee H, Zwisler AD, et al. Cardiac rehabilitation in Europe: results from the European Cardiac Rehabilitation Inventory Survey. Eur J Cardiovasc Prev Rehabil 2010;17:410-18.

9. Suaya JA, Shepard DS, Normand SL, et al. Use of cardiac rehabilitation by Medicare beneficiaries after myocardial infarction or coronary bypass surgery. Circulation 2007;116:1653-62.

10. Goto $\mathrm{Y}$, Itoh $\mathrm{H}$, Adachi $\mathrm{H}$, et al. Use of exercise cardiac rehabilitation after acute myocardial infarction. Circ J 2003;67:411-15.

11. Goto Y, Saito M, Iwasaka T, et al. Poor implementation of cardiac rehabilitation despite broad dissemination of coronary interventions for acute myocardial infarction in Japan: a nationwide survey. Circ $J$ 2007;71:173-9.

12. Ali-Faisal SF, Benz SL, Johnston L. Cardiac rehabilitation referral and enrolment across an academic health sciences centre with eReferral and peer navigation: a randomised controlled pilot trial. BMJ Open 2016;6:e010214.

13. Aragam KG, Dai D, Neely ML, et al. Gaps in referral to cardiac rehabilitation of patients undergoing percutaneous coronary intervention in the United States. J Am Coll Cardiol 2015;65:2079-88.

14. Colbert JD, Martin BJ, Haykowsky MJ, et al. Cardiac rehabilitation referral, attendance and mortality in women. Eur J Prev Cardiol 2015:22:979-86.

15. Stelfox HT, Straus SE, Nathens A, et al. Evidence for quality indicators to evaluate adult trauma care: a systematic review. Crit Care Med 2011;39:846-59.

16. Stang AS, Straus SE, Crotts J, et al. Quality indicators for high acuity pediatric conditions. Pediatrics 2013;132:752-62.

17. Albert JM, Das P. Quality indicators in radiation oncology Int J Radiat Oncol Biol Phys 2013;85:904-11.

18. Higashi T. Lessons learned in the development of process quality indicators for cancer care in Japan. Biopsychosoc Med 2010;4:14

19. Campbell SM, Ludt S, Van Lieshout J, et al. Quality indicators for the prevention and management of cardiovascular disease in primary care in nine European countries. Eur J Cardiovasc Prev Rehabil 2008;15:509-15.

20. Thomas RJ, King M, Lui K, et al. AACVPR/ACC/AHA 2007 performance measures on cardiac rehabilitation for referral to and delivery of cardiac rehabilitation/secondary prevention services endorsed by the American College of Chest Physicians, American College of Sports Medicine, American Physical Therapy Association, Canadian Association of Cardiac Rehabilitation, European Association for Cardiovascular Prevention and Rehabilitation, Inter-American Heart Foundation, National Association of Clinical Nurse Specialists, Preventive Cardiovascular Nurses Association, and the Society of Thoracic Surgeons. J Am Coll Cardiol 2007:50:1400-33.

21. Thomas RJ, King M, Lui K, et al. AACVPR/ACCF/AHA 2010 Update performance measures on cardiac rehabilitation for referral to cardiac rehabilitation/secondary prevention services endorsed by the American College of Chest Physicians, the American College of Sports Medicine, the American Physical Therapy Association, the Canadian Association of Cardiac Rehabilitation, the Clinical Exercise Physiology Association, the European Association for Cardiovascular Prevention and Rehabilitation, the Inter-American Heart Foundation, The National Association of Clinical Nurse Specialists, the Preventive Cardiovascular Nurses Association, and the Society of Thoracic Surgeons. J Am Coll Cardiol 2010;56:1159-67.

22. Grace SL, Poirier P, Norris CM, et al. Pan-Canadian development of cardiac rehabilitation and secondary prevention quality indicators. Can J Cardiol 2014;30:945-8.

23. Van Engen-Verheul $\mathrm{M}$, Kemps $\mathrm{H}$, Kraaijenhagen $\mathrm{R}$, et al. Modified Rand method to derive quality indicators: a case study in cardiac rehabilitation. Stud Health Technol Inform 2011;169:88-92.

24. Kötter T, Blozik E, Scherer M. Methods for the guideline-based development of quality indicators-a systematic review. Implement Sci 2012;7:21.

25. Bobrovitz N, Parrilla JS, Santana M, et al. A qualitative analysis of a consensus process to develop quality indicators of injury care. Implement Sci 2013;8:45.

26. Thomas RJ, Chiu JS, Goff DC, et al. Reliability of abstracting performance measures: results of the cardiac rehabilitation referral and reliability (CR3) project. J Cardiopulm Rehabil Prev 2014;34:172-9.

27. Grace SL, Tan Y, Oh P, et al. Feasibility of assessing 2 cardiac rehabilitation quality indicators. J Cardiopulm Rehabil Prev 2016;36:112-16.

28. Fitch K. The Rand/UCLA appropriateness method user's manual. Santa Monica: Rand, 2001.

29. Shekelle PG, Ortiz E, Rhodes S, et al. Validity of the agency for healthcare research and quality clinical practice guidelines: how quickly do guidelines become outdated? JAMA 2001;286:1461-7.

30. Alonso-Coello P, Martínez García L, Carrasco JM, et al. The updating of clinical practice guidelines: insights from an international survey. Implement Sci 2011;6:107.

31. Brouwers MC, Kho ME, Browman GP, et al. AGREE II: advancing guideline development, reporting and evaluation in health care. CMAJ 2010;182:E839-42.

32. Spertus JA, Eagle KA, Krumholz HM, et al. American College of Cardiology and American Heart Association methodology for the selection and creation of performance measures for quantifying the quality of cardiovascular care. J Am Coll Cardiol 2005;45:1147-56.

33. Institute for Clinical Systems Improvement (ICSI). Diagnosis and treatment of chest pain and acute coronary syndrome (ACS). 6th edn. Bloomington, MN: Institute for Clinical Systems Improvement (ICSI), 2010:85

34. Acute Coronary Syndrome Guidelines Working Group. Guidelines for the management of acute coronary syndromes 2006. Med J Aust 2006;184(Suppl 8):S9-29.

35. New Zealand Guidelines Group. New Zealand cardiovascular guidelines handbook [electronic resource]: a summary resource for primary care practitioners. 2009. http://www.moh.govt.nz/NoteBook/ nbbooks.nst/0/9874D7743DE4CCA9CC2579E2007E4FA2/\$file/ cardiovascular-guidelines-handbook.pdf (accessed 18 Nov 2016).

36. National Collaborating Centre for Primary Care. MI: secondary prevention-secondary prevention in primary and secondary care for patients following a myocardial infarction [NICE clinical guideline 48]. London: National Institute for Health and Clinical Excellence, 2007. http://almacen-gpc.dynalias.org/publico/Prevencion secundaria tras infarto NICE.pdf (accessed 18 Nov 2016).

37. National Clinical Guideline Centre (UK). Unstable angina and NSTEMI: the early management of unstable angina and non-ST-segment-elevation myocardial infarction. London: Royal College of Physicians (UK), 2010. (NICE Clinical Guidelines, No. 
94.) https://www.ncbi.nlm.nih.gov/books/NBK62742/ (accessed 10 Jan 2017).

38. Antman EM, Hand M, Armstrong PW, et al. 2007 focused update of the ACC/AHA 2004 guidelines for the management of patients with ST-elevation myocardial infarction: a report of the American College of Cardiology/American Heart Association Task Force on Practice Guidelines. J Am Coll Cardiol 2008;51:210-47.

39. Mosca L, Benjamin EJ, Berra K, et al. Effectiveness-based guidelines for the prevention of cardiovascular disease in women2011 update: a guideline from the American Heart Association. J Am Coll Cardiol 2011;57:1404-23.

40. Graham I, Atar D, Borch-Johnsen K, et al. European guidelines on cardiovascular disease prevention in clinical practice: executive summary: Fourth Joint Task Force of the European Society of Cardiology and Other Societies on Cardiovascular Disease Prevention in Clinical Practice (constituted by representatives of nine societies and by invited experts). Eur Heart J 2007;28:2375-414.

41. Mosca L, Banka CL, Benjamin EJ, et al. Evidence-based guidelines for cardiovascular disease prevention in women: 2007 update. J Am Coll Cardiol 2007;49:1230-50.

42. Anderson JL, Adams CD, Antman EM, et al. ACC/AHA 2007 guidelines for the management of patients with unstable angina/ non-ST-elevation myocardial infarction: a report of the American College of Cardiology/American Heart Association Task Force on Practice Guidelines (Writing Committee to revise the 2002 guidelines for the management of patients with unstable angina/non-STelevation myocardial infarction) developed in collaboration with the American College of Emergency Physicians, the Society for Cardiovascular Angiography and Interventions, and the Society of Thoracic Surgeons endorsed by the American Association of Cardiovascular and Pulmonary Rehabilitation and the Society for Academic Emergency Medicine. J Am Coll Cardiol 2007;50:e1-e157.

43. Bassand JP, Hamm CW, Ardissino D, et al. Guidelines for the diagnosis and treatment of non-ST-segment elevation acute coronary syndromes. Eur Heart J 2007;28:1598-660.

44. Hamm CW, Bassand JP, Agewall S, et al. ESC guidelines for the management of acute coronary syndromes in patients presenting without persistent ST-segment elevation: the Task Force for the management of acute coronary syndromes (ACS) in patients presenting without persistent ST-segment elevation of the European Society of Cardiology (ESC). Eur Heart J 2011;32:2999-3054.

45. Rydén L, Standl E, Bartnik M, et al. Guidelines on diabetes, pre-diabetes, and cardiovascular diseases: executive summary. The Task Force on Diabetes and Cardiovascular Diseases of the European Society of Cardiology (ESC) and of the European Association for the Study of Diabetes (EASD). Eur Heart $J$ 2007;28:88-136.

46. Cooper A, Skinner J, Nherera L, et al., Clinical Guidelines and Evidence Review for Post Myocardial Infarction. Secondary prevention in primary and secondary care for patients following a myocardial infarction. London: National Collaborating Centre for
Primary Care and Royal College of General Practitioners, 2007. http://Inx.mednemo.it/wp-content/uploads/2009/09/ CG48FullGuideline.pdf (accessed 18 Nov 2016)

47. Van de Werf F, Bax J, Betriu A, et al. Management of acute myocardial infarction in patients presenting with persistent ST-segment elevation: the Task Force on the management of ST-segment elevation acute myocardial infarction of the European Society of Cardiology. Eur Heart J 2008;29:2909-45.

48. JCS Joint Working Group. Guidelines for Rehabilitation in Patients with Cardiovascular Disease (JCS 2007). 2007. http://www.j-circ.or jp/guideline/pdf/JCS2007_nohara_h.pdf (accessed 18 Nov 2016).

49. JCS Joint Working Group. Guidelines for Secondary Prevention of Myocardial Infarction (JCS2006). 2006. http://www.j-circ.or.jp/ guideline/pdf/JCS2006_ishikawa_h.pdf (accessed 18 Nov 2016).

50. JCS Joint Working Group. Guidelines for the primary prevention of ischemic heart disease revised version (JCS 2006). 2006. http:// minds.jcqhc.or.jp/n/med/4/med0048/G0000131/0002 (accessed 18 Nov 2016).

51. JCS Joint Working Group. Guidelines for the management of patients with ST-elevation myocardial infarction (JCS 2008). Circ J 2008;72(Suppl IV):1347-442.

52. JCS Joint Working Group. Guidelines for Exercise Eligibility at Schools, Work-Sites, and Sports in Patients with Heart Diseases (JCS 2008). 2008. http://www.j-circ.or.jp/guideline/pdf/JCS2008_ nagashima_h.pdf (accessed 18 Nov 2016).

53. JCS Joint Working Group. Guidelines for the management of cardiac diseases complicated with cerebrovascular disease, chronic kidney disease, or peripheral vascular disease. (JCS 2008). Circ J 2008;72 (Suppl IV):1465-544.

54. JCS Joint Working Group. Guidelines for Smoking Cessation (JCS 2010). 2010. http://www.j-circ.or.jp/guideline/pdf/JCS2010murohara. h.pdf (accessed 18 Nov 2016).

55. The Japanese Society of Hypertension. The Japanese Society of Hypertension Guidelines for the Management of Hypertension (JSH 2009). 2009. http://minds.jcqhc.or.jp/n/med/4/med0019/G0000180/ 0001 (accessed 18 Nov 2016)

56. JCS Joint Working Group. Guidelines for Secondary Prevention of Myocardial Infarction (JCS 2011). Circ J 2013;77:231-48.

57. Wollersheim $\mathrm{H}$, Hermens $\mathrm{R}$, Hulscher $\mathrm{M}$, et al. Clinical indicators: development and applications. Neth J Med 2007;65:15-22.

58. Hommel I, van Gurp PJ, Tack CJ, et al. Perioperative diabetes care: development and validation of quality indicators throughout the entire hospital care pathway. BMJ Qual Saf 2016;25:525-34.

59. JCS Joint Working Group. Guidelines for rehabilitation in patients with cardiovascular disease (JCS 2012). Circ J 2014;78:2022-93.

60. Marshall MN, Shekelle PG, McGlynn EA, et al. Can health care quality indicators be transferred between countries? Qual Saf Health Care 2003;12:8-12.

61. Haynes RB, Devereaux PJ, Guyatt GH. Clinical expertise in the era of evidence-based medicine and patient choice. ACP J Club 2002;136:A11-14. 